Anales de Geografía de la Universidad Complutense ISSN: 0211-9803

http://dx.doi.org/10.5209/AGUC.72978

\title{
Cartografía y promoción turística en espacios de frontera interautonómica: el caso de Els Ports (Cataluña, Aragón y Comunidad Valenciana)
}

\author{
Ramon Galindo Caldés ${ }^{1}$; Albert Santasusagna Riu ${ }^{2}$ \\ Recibido: 2 de mayo del 2020 / Enviado a evaluar: 17 de junio del 2020 / Aceptado: 15 de diciembre del 2020
}

\begin{abstract}
Resumen. En nuestro artículo tratamos de analizar la incidencia del ordenamiento jurídico diferenciado en la política pública del turismo a partir de un análisis centrado en el espacio de "frontera" entre las comunidades autónomas de Cataluña, Aragón y la Comunidad Valenciana. Se trata de un territorio que sufre la falta de actividades económicas y en el que el sector turístico es especialmente relevante para su desarrollo. La carencia de instrumentos de cooperación interautonómica eficaces, así como una ausencia de una cultura de la cooperación, no permite la concepción de una política común para el desarrollo sinérgico del territorio. No obstante, existen iniciativas que marcan un punto de inflexión en este sentido: el proyecto Tres Territoris, de reciente creación, trata de aunar esfuerzos a favor de la creación de un espacio supracomarcal que maximice la oferta turística del macizo de Els Ports. Lo hace a través de un mapa común, como primer paso para la colaboración en la dinamización de la oferta turística en el conjunto del territorio.
\end{abstract}

Palabras clave: Fronteras interautonómicas; cooperación interautonómica; política institucional; turismo interior.

[en] Cartography and tourism promotion in internal border areas: the case of Els Ports (Catalonia, Aragon and the Valencian Community)

Abstract. The aim of this paper is to seek the incidence of differentiated legal order in the public policy
of tourism from analysis focused on the "border" space between the Spanish Autonomous Communities
of Catalonia, Aragon and the Valencian Community. Our study area suffers from a lack of economic
activities and the tourism sector is especially relevant for its development. The absence of effective inter-
autonomous cooperation tools, as well as a very poor culture of cooperation, does not allow the
conception of a whole common policy. However, there are initiatives that mark a turning point. The

1 Universitat Oberta de Catalunya. Estudios de Derecho y Ciencia Política. Barcelona, España.

E-mail: rgalindoca@uoc.edu

2 Universitat de Barcelona. Departamento de Geografía. Barcelona, España.

E-mail: asantasusagna@ub.edu 
recently created Tres Territoris project tries to unite efforts in favour of the creation of a supra-regional space that maximizes the tourist offer of the Els Ports massif. It does so through a common map, as a first step for collaboration in boosting the tourist offer in the whole of the territory.

Key words: Inter-regional borders; inter-regional cooperation; institutional policy; inland tourism.

\section{[fr] Cartographie et promotion touristique dans les zones de frontière inter- autonome: le cas d'Els Ports (Catalogne, Aragon et Communauté valencienne)}

Résumé. Cet article tente de déterminer l'incidence de l'ordonnément juridique différencié dans la politique publique du tourisme à partir d'une analyse centrée sur l'espace "frontalier" entre les Communautés autonomes espagnoles de Catalogne, d'Aragon et de la Communauté valencienne. Notre zone d'étude souffre d'un manque d'activités économiques et le secteur du tourisme est particulièrement pertinent pour son développement. L'absence d'outils de coopération inter-autonomes efficaces, ainsi qu'une culture de coopération très médiocre, ne permettent pas de concevoir toute une politique commune. Cependant, certaines initiatives marquent un tournant. Le projet Tres Territoris récemment créé tente d'unir les efforts en faveur de la création d'un espace suprarégional qui maximise l'offre touristique du massif d'Els Ports. Cette initiative s'est faite à travers une carte commune, dans un premier temps de collaboration pour dynamiser l'offre touristique sur l'ensemble du territoire.

Mots clés: Frontières inter-autonomes; coopération inter-autonome; politique institutionnelle; tourisme intérieur.

Cómo citar. Galindo Caldés, R. y Santasusagna Riu, A. (2020): Cartografía y promoción turística en espacios de frontera interautonómica: el caso de Els Ports (Cataluña, Aragón y Comunidad Valenciana). Anales de Geografía de la Universidad Complutense, 40(2), 345-372.

Sumario. 1. Introducción. 2. La cartografía en la promoción turística. 2.1. La cartografía como constructora de espacios. 2.2. Un apunte sobre cartografía y límites administrativos. 2.3. La cartografía turística como instrumento de promoción. 3. Els Ports como espacio natural transfronterizo. 4. La división administrativa en un entorno institucional complejo. 4.1 Una compleja trama institucional. 4.2. Entes "transfronterizos". 4.3. La división del macizo: diferentes niveles de protección. 5. La promoción del turismo en Els Ports. 5.1. La competencia en turismo: divergencia y diversidad. 5.2. Escenario multinivel y falta de cooperación entre administraciones. 5.3. Una promoción turística diferenciadora y segregadora. 5.4. La necesidad de cooperar: el mapa como oportunidad. 5.5. Las dificultades para articular una fórmula de cooperación. 5.5.1. Las dinámicas divergentes de promoción turística. 5.5.2. Las opciones: personificadas o no, públicas o de gestión privada. 6. Reflexiones finales. 7. Bibliografía.

\section{Introducción}

La descentralización en el Estado autonómico ha tenido como consecuencia un progresivo distanciamiento entre los ordenamientos jurídicos de cada una de las Comunidades autónomas, y también la puesta en marcha de políticas públicas de distinto signo en cada una de ellas. Ello tiene un reflejo claro en lo que a la regulación del turismo y de las políticas turísticas se refiere. Sin embargo, el desarrollo normativo y las políticas autonómicas han ignorado que parte de los recursos turísticos se sitúan en un ámbito de frontera interautonómica, de forma que los activos en ambas franjas del límite administrativo son similares o incluso, en algunos casos, 
indistinguibles. Se trata, fundamentalmente, de recursos en los que el límite administrativo generalmente es un curso fluvial -como lo son, por ejemplo, los ríos Algars, Cinca, Ebro o Noguera Ribagorzana en la frontera trazada entre Cataluña, Aragón y la Comunidad Valenciana- que articula los recursos turísticos -pesca deportiva, deporte activo, patrimonio natural y cultural-, pero que lo hace de forma independiente, generando una regulación, unas políticas y una oferta turísticas separadas y, generalmente, sin tener en cuenta la otra parte.

Los problemas que genera esta situación son evidentes y provocan disfunciones de tipo normativo y de aplicación de políticas que pueden llegar a ser incluso contradictorias-, pero también tienen como consecuencia una oferta turística que pierde gran parte de su potencial. Ello es importante en un territorio que generalmente sufre de la falta de actividades económicas y que provoca que el sector turístico sea especialmente relevante para su desarrollo. A nivel práctico se producen numerosas disfunciones que dificultan superar dicha situación, como es la falta de instrumentos de cooperación eficaces entre municipios y comarcas de ambas comunidades, así como la ausencia de una cultura de la cooperación, que sea consciente de los beneficios de una regulación, una política y una oferta turística conjunta para los activos en este territorio de frontera. La cartografía turística en este sentido es muy ilustrativa de esta situación, ya que una simple observación de cualquier mapa de promoción turística nos muestra sólo uno de los territorios, viendo el vecino no como "complemento" sino como "competencia".

En nuestro trabajo analizamos un caso concreto que intenta superar todos estos problemas con un instrumento que puede parecer muy sencillo, como es la generación de un mapa conjunto de tres comarcas: Els Ports (Castellón), Matarranya (Teruel) y Terra Alta (Tarragona). Con esta iniciativa, denominada "Tres Territoris", se intenta generar un espacio supracomarcal que maximice la oferta turística del entorno del macizo de Els Ports, espacio territorial que se encuentra dividido por diferentes normas, grados de protección ambiental, políticas de promoción, etc. Lo hace a través de la capacidad de la cartografía de generar conciencia sobre la existencia de un espacio común y compartido.

\section{La cartografía en la promoción turística}

\subsection{La cartografía como constructora de espacios}

El objetivo histórico y científico de la cartografía es conseguir una representación fiable de la realidad geográfica. La creación de un mapa es, pues, imprescindible para la comprensión integral del territorio y de sus variables físicas y humanas $-\mathrm{y}$ no solamente en el espacio, sino en el tiempo: el estudio de la llamada cartografía histórica es prueba de ello. No obstante, la cartografía no es una herramienta desprovista de intencionalidades: un mapa puede cumplir con el objetivo de representar la realidad, u optar por mostrar solo una parte de ella (una realidad: la que el cartógrafo desea mostrar, sobrerepresentar u ocultar al lector). No en vano, 
Farinelli (2003) destaca que para el análisis geográfico de la realidad es necesario comprender lo que se ve y lo que no, lo que emana de las formas físicas y lo que deriva de sus códigos subjetivos (las instituciones civiles y religiosas y las relaciones económicas: en definitiva, la abstracción del poder). Por lo tanto, la cartografía no es una herramienta que funcione solo y exclusivamente para representar un espacio objetivo, sino también para influir en lo subjetivo y, por lo tanto, construir nuevas realidades.

En base a todo lo expuesto, un mapa también puede constituir el reflejo del discurso o pensamiento imperante. Tal y como afirma Montoya (2007), el mapa, desde sus inicios como herramienta de valor para los sapiens -varios miles de años antes de la concepción de la cartografía como ciencia institucionalizada, en el siglo XIX-, ha lidiado con una doble función: por una parte, como un instrumento de representación matemática y precisa de la realidad; por otra, como una interpretación de la imagen del mundo (una imagen que encarna los valores intangibles de lo político, lo religioso y lo cosmológico). Por lo tanto, "un cartógrafo es un sujeto social, sumido en la red de intereses políticos que configuran la realidad social de su tiempo, su conocimiento no es neutro ni imparcial, está inserto en las tramas de poder y su conocimiento es instrumentalizado por aquel" (Montoya, 2007:163). Según este punto de vista, que bebe de pensadores anglosajones como Harley (2001), un mapa presenta una carga simbólica que lo convierte en un producto cultural de las relaciones de poder existentes -y que, por lo tanto, caracteriza al cartógrafo. Es nuestro objetivo, en el marco del presente artículo, identificar y sintetizar estas variables subjetivas inherentes a la cartografía focalizadas y estudiadas en un caso concreto que expondremos en los siguientes apartados. Antes de ello, es conveniente realizar una serie de apuntes y consideraciones previas necesarias para la contextualización del estudio.

\subsection{Un apunte sobre cartografía y límites administrativos}

Los límites configuran uno de los datos más importantes de una base cartográfica, pues representan las divisiones administrativas de un Estado (límites que, en la misma línea del anterior epígrafe, constituyen la base de las relaciones históricas y subjetivas del poder). En el caso español, la cartografía administrativa representa los límites entre las autonomías, las provincias y los municipios, así como otras divisiones históricas como las comarcas. La delimitación correcta del territorio es fundamental, pues "permite al ciudadano conocer hasta donde puede aplicar sus derechos y obligaciones; al igual que permite a la administración aplicar su jurisdicción" (Femenia-Ribera et al., 2013).

En este sentido, la Ley Reguladora de las Bases del Régimen Local es la norma básica que regula los deslindes entre administraciones en España, pero no se encuentra exenta de multitud de problemas e interpretaciones entre términos municipales -hecho que lleva, en algunos casos, al conflicto entre distintas comunidades autónomas. Tal y como afirman los autores citados anteriormente, en España encontramos varios casos "en los que existe una indefinición de los propios 
límites por la diversidad en las técnicas topográficas y cartográficas utilizadas para definirlo; ello ha llevado a que, en muchos casos, conociendo inicialmente la delimitación clara del territorio, la mala representación posterior ha llevado a distorsionar esta información gráfica, provocando, a la larga, graves problemas" (Femenia-Ribera et al., 2013). Así pues, uno de los principales problemas de la cartografía de la división administrativa es, precisamente, las interpretaciones históricas y desiguales de los límites, que ponen en entredicho municipios y comunidades autónomas. A ello se le añaden otras problemáticas inherentes a la complejidad administrativa, como lo es la superposición de límites (autonómicos, provinciales, municipales) que, en ciertas circunstancias, no coinciden y suponen distintos niveles de institucionalización. A ello también nos referiremos, en el marco de un caso concreto, a lo largo del artículo.

\subsection{La cartografía turística como instrumento de promoción}

La promoción turística recurre a la cartografía como una herramienta de referencia espacial para un determinado público (el turista). Este hecho condiciona totalmente su objetivo, pues esta no busca la representación y jerarquización de la totalidad de los entes geográficos, sino que prioriza los puntos y las zonas que implican un interés turístico (Balsa \& Lois, 2010). Además, la cartografía turística no acostumbra a ofrecerse en un soporte físico individualizado -como podría ser, por ejemplo, un mapa oficial de carreteras-, sino que comúnmente forma parte de una revista o un folleto en el que se incluye otra información de interés turístico. Así pues, la cartografía turística busca resaltar los elementos gráficos por encima de los textuales o densamente informativos, y prioriza ciertas áreas gravitacionales -los atractivos naturales y culturales, los equipamientos, las infraestructuras principales, los servicios turísticos o las terminales ferroviarias y aeroportuarias, entre otros espacios-, ciertos nodos -parques y zonas verdes, centros comerciales, plazas, barrios, edificios peculiares o zoológicos, entre otros tantos- y ciertos límites que configuran el espacio de interés (Miranda, 2006). Por lo tanto, con esta selección (interesada) los mapas turísticos también contribuyen a la construcción social de una determinada imagen turística del espacio -imagen que, en según qué casos, conduce a una vulgarización (Domínguez-Mújica, 2007) o una estereotipificación (Navas, 2016) de la representación sintética del territorio. Tal y como sugieren determinados autores, la cartografía turística "en un sentido amplio pretende incluir no sólo aquellos mapas temáticos que organizan datos estadísticos o informaciones puntuales sobre el turismo sino -sobre todo- también aquellos que interpelan a un potencial turista (tanto para sugerirle modos de practicar el turismo como para proponerle imágenes acerca de los atractivos y destinos turísticos)" (Almirón et al., 2007).

La cartografía turística es realizada por una gran diversidad de agentes del territorio, tanto pertenecientes a la esfera pública (principalmente, oficinas e instituciones gubernamentales del turismo) como privada (empresas prestadoras de servicios turísticos u organismos privados vinculados a la práctica del turismo). Esto conlleva a una diferencia básica: mientras que la cartografía turística realizada por 
organismos públicos tiene el objetivo de cumplir con las directrices propias de la política turística, la generada por organismos privados no tiene por qué cumplir con esta obligación (Almirón et al., 2007). Esto no solo conlleva una promoción individualizada de productos y actividades turísticas -llevadas a cabo, lógicamente, por quien o quienes construyen el mapa-, sino que existe también una priorización y jerarquización independiente de los espacios y zonas de interés -hecho que implica, a su vez, diversas construcciones de lo turístico: tantas imágenes como entes privados existan dedicados a esta empresa. Por lo tanto, es de vital importancia conocer el origen (privado o público) de la cartografía para proceder a su interpretación como instrumento de promoción turística. Un hecho que, a lo largo del artículo, tendremos ocasión de valorar.

\section{Els Ports como espacio natural transfronterizo}

Els Ports -conocidos, también, como los puertos de Tortosa-Beceite, por su localización geográfica- es un macizo montañoso de más de $800 \mathrm{~km}^{2}$ formado por varias sierras - entre las que destacan, por ejemplo, los puertos de Paüls y de Alfarasituado entre las provincias de Tarragona (Cataluña), Teruel (Aragón) y Castellón (Comunidad Valenciana), extendiéndose entre la localidad catalana de Prat de Comte hasta la montaña catalanovalenciana del Tossal d'en Cervera y la comarca natural valenciana de la Tinença de Benifassà. Su punto culminante es el llamado Mont Caro $(1.447 \mathrm{~m})$, en el municipio tarraconense de Roquetes, pero también destaca el llamado Tossal del Rei $(1.356 \mathrm{~m})$-o también conocido popularmente como el Tossal dels Tres Reis, en referencia al punto de encuentro de los antiguos reinos de la Corona de Aragón. Els Ports no deben confundirse con Ports de Morella, nombre que recibe el conjunto orográfico situado en el extremo septentrional del Sistema ibérico valenciano y que da lugar, también, al nombre de la comarca interior y montañosa de la provincia valenciana de Castellón -territorio que, por otra parte, también es protagonista de nuestro estudio.

El macizo representa la franja de contacto por excelencia entre la Cordillera Prelitoral catalana y el Sistema ibérico, y a su vez entre las comarcas catalanas del Baix Ebre y el Montsià, al este, y la Terra Alta, al noroeste; la comarca aragonesa del Matarranya (también al noroeste) $\mathrm{y}$, finalmente, la comarca costera valenciana del Baix Maestrat al sur. El macizo se orienta de noroeste a suroeste, y su relieve es abrupto, sobretodo en su vertiente marítima. Su sustrato geológico está formado por calcáreas y dolomías mesozoicas. Sus dos vertientes difieren en condiciones climáticas y composición vegetal. La vertiente sureste, litoral y mediterránea, presenta un régimen de temperaturas mucho más suaves que la vertiente interior, de condiciones más propiamente continentales. De la misma forma, la vertiente costera está cubierta por encinar litoral y maquia, mientras que en la continental abunda el encinar montano y el carrascal.

Gracias a su patrimonio natural y cultural, Els Ports constituye uno de los espacios naturales con mayor potencial turístico en el ámbito de montaña catalán (Torres-Solé 
et al., 2015), conjuntamente a la cordillera pirenaica, la sierra de Montsant y el Montseny. El área de más de 30.000 hectáreas protegida bajo la denominación de Parque Natural de Els Ports - catalogada como espacio de interés natural en 2001 y circunscrita exclusivamente en la provincia de Tarragona- es una de las más extensas del conjunto de parques naturales de Cataluña -solo superada por el Parque Natural del Cadí-Moixeró, de aproximadamente 40.000 hectáreas. Además, el parque integra también una reserva natural parcial (denominada, en catalán, les Fagedes dels Ports). Por otra parte, es importante comentar que las tres comunidades autónomas comparten la gestión de la llamada Reserva Nacional de Caza de Els Ports de Tortosa y Beceite -creada en 1966, en período franquista-, integrada por una superficie muy parecida a la del parque natural (casi 29.000 hectáreas) y nueve municipios (siete catalanes: Alfara de Carles, Roquetes, Tortosa, Mas de Barberans, La Sénia, Arnes y Horta de Sant Joan; uno de aragonés: Beseit; y uno de valenciano: la Pobla de Benifassà).

Figura 1. Localización geográfica de Els Ports, en relación a otros accidentes geográficos de relevancia entre Cataluña, Aragón y la Comunidad Valenciana.

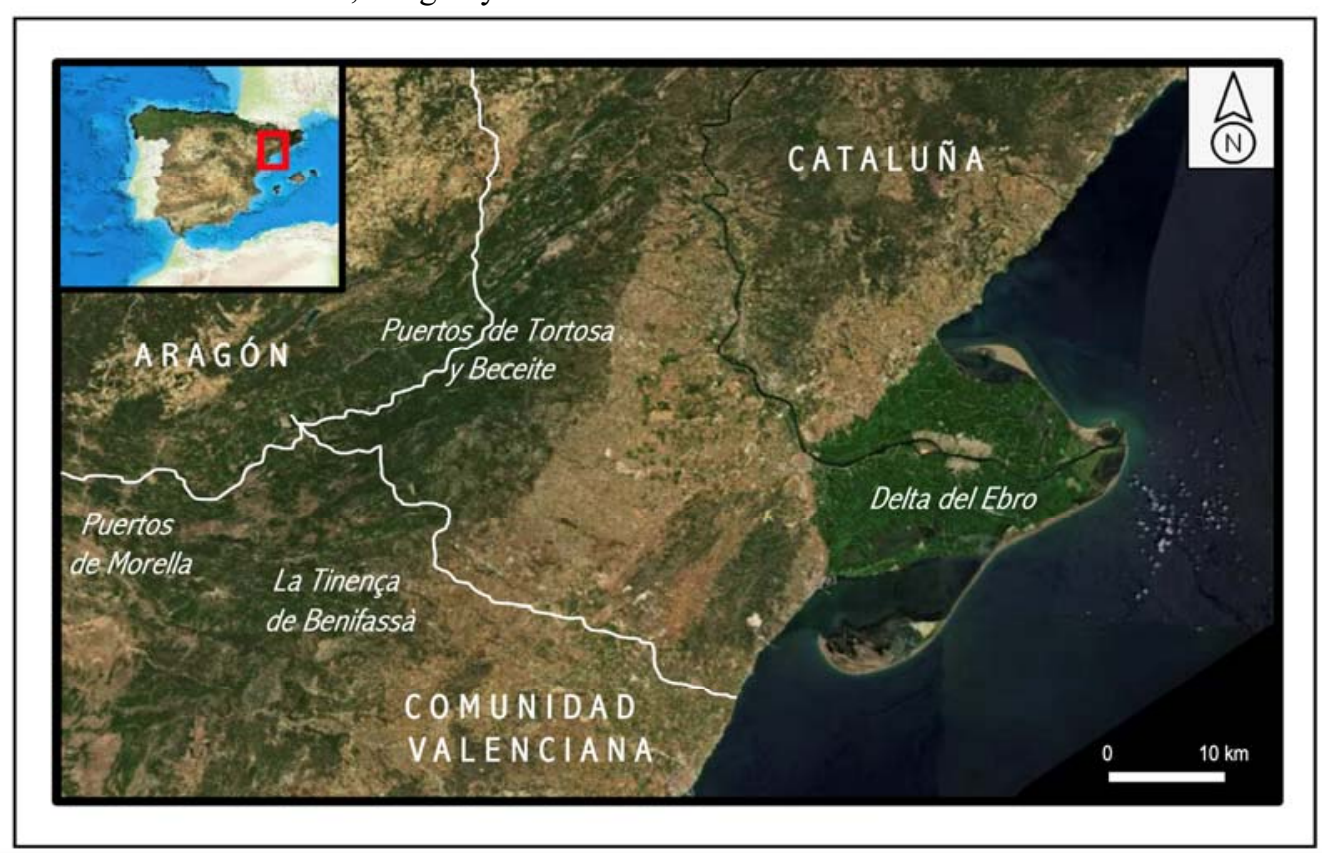

Fuente: Elaboración propia a partir de datos ortofotográficos del Instituto Geográfico Nacional (IGN).

Los principales tipos de turismo que se desarrollan en nuestro ámbito de estudio es el turismo de naturaleza y de aventura -ligado a una gran diversidad de actividades deportivas tales como la escalada, la espeleología, los baños fluviales o el barranquismo (Teruel et al., 2014). No obstante, el turismo rural también tiene una 
gran importancia. En este contexto, el Ecomuseu dels Ports de Beseit, situado en el municipio catalán de Horta de Sant Joan y especializado en la divulgación del patrimonio natural del Parque Natural de Els Ports (Vilanova, 2014), es uno de los principales focos de atracción para el turista que explora actividades culturales además de constituir uno de los principales ecomuseos de Cataluña (Cors, 2009). Este ecomuseo actúa, además, como el enclave territorial por excelencia de donde parte un itinerario cultural radial que se expande por toda la zona interautonómica (Franquesa, 2012), y que tiene como aliados más próximos el centro Picasso, el Mas de Quiquet, el convento de San Salvador y el olivo milenario Lo Parot. El macizo dels Ports también es un centro importante de turismo cinegético (Pallarés, 2013), hecho que comparte con la comarca valenciana homónima, y que tiene en la ciudad de Morella un referente -donde, anualmente, se celebra la tradicional Feria de Caza. Los productos gastronómicos también constituyen una referencia en la zona, sobretodo el aceite -que dispone de una denominación oficial diferenciada en cada comunidad autónoma: por una parte, la DO Terra Alta; por la otra, la DO Bajo Aragón- y las setas -que la administración procura fomentar y potenciar como turismo gastronómico.

En todo caso, Els Ports es un espacio donde, a partir de la planificación territorial -su constitución como reserva de caza en los sesenta, y su conversión a parque natural, en la franja catalana, a principios del nuevo mileno-, las actividades turísticas se han visto ordenadas, fomentadas y multiplicadas a lo largo de las últimas décadas. Es un ejemplo de espacio con gran potencial turístico, aunque todavía no desarrollado de forma suficiente $-\mathrm{y}$ con ciertas desigualdades en su gestión diferencial por comunidades autónomas (Capellà-Miternique, 2002). Algunos de los casos que estudiamos en este artículo son, precisamente, ejemplos de esta voluntad que surge de los distintos agentes del territorio.

\section{La división administrativa en un entorno institucional complejo}

\subsection{Una compleja trama institucional}

Como ya hemos visto, el macizo de Els Ports se sitúa en una encrucijada entre tres comunidades autónomas: Cataluña, Aragón y Comunidad Valenciana. Ello supone que cada una de las tres partes en que se divide el macizo está sometida a normas diferentes. En lo que a nosotros nos atañe, esto significa diferente regulación ambiental, urbanística, turística, etc. También operan en el territorio diferentes entes instrumentales, como la Agència Catalana de l'Aigua (ACA), o entes de titularidad estatal, como la Conferencia Hidrográfica del Ebro (CHE). La división administrativa entre las tres CCAA no es más que una de las piezas del entramado institucional en que se divide el territorio que abordamos. En primer lugar, de la misma forma que encontramos una división autonómica, también lo es provincial. En efecto, el territorio de Els Ports se divide entre las provincias de Tarragona, Castellón y Teruel. Si avanzamos un nivel más vemos que el territorio está también dividido entre seis 
comarcas: tres catalanas (Montsià, Baix Ebre y Terra Alta), dos valencianas (Baix Maestrat y Els Ports) y una aragonesa (Matarranya). Su nivel de institucionalización es variable. Así, encontramos que los consejos comarcales catalanes son los que han adquirido una mayor fortaleza competencial y en recursos, mientras que las comarcas aragonesas tienen una significación menor. Por otra parte, no existen administraciones comarcales en la Comunidad Valenciana, por lo que sólo encontramos la Mancomunitat Comarcal dels Ports, formada por municipios de las comarcas de Els Ports, Alt Maestrat y Baix Maestrat ${ }^{3}$. El grado de intervención pública en el territorio analizado es por tanto variable. El último nivel administrativo es el municipal, en el que incluiríamos diferentes municipios, en función de qué consideremos en nuestro análisis. Un total de 25 de ellos es adyacente al límite administrativo entre dos comunidades autónomas, aunque es evidente que el número es mucho mayor si incluimos una segunda corona de municipios o incluso el del conjunto de las comarcas, en cuyo caso sobrepasaríamos el centenar. En cualquier caso, lo que nos interesa poner de manifiesto aquí es la multiplicidad de administraciones que operan en un territorio de gran extensión pero poca población, con los problemas que el mundo rural tiene en general de envejecimiento, dificultad de comunicaciones, escasa actividad económica, etc. El turismo de interior en zonas rurales en este contexto puede convertirse en una oportunidad para el desarrollo local, aprovechando sus recursos naturales y patrimoniales (Cànoves et. Al., 2017: 244), aunque como ya se ha advertido respecto al territorio que analizamos, deben conjugarse los intereses diversos existentes en el territorio, evitando la folklorización del medio rural (Capellà, 2002). En un territorio periférico y dependiente como el que analizamos, el papel del sector público es vital. En este contexto, la fragmentación de la acción pública en la promoción turística dificulta la implementación de políticas efectivas. Dicha fragmentación no se produce sólo en lo que se refiere a las políticas públicas, sino en la existencia de tres ordenamientos jurídicos diferentes, que regulan una misma actividad en un territorio dotado de cierta unidad geográfica. Las relaciones jurídicas son un fenómeno espacial. Las normas crean espacios y al mismo tiempo su aplicación está condicionada por dichas construcciones legales. En la aplicación de las normas en un entorno fronterizo nos encontramos con disfunciones producidas por dos normas que regulan de forma distinta un mismo fenómeno (Galindo, 2018). El resultado es que se producen situaciones desiguales en diferentes

\footnotetext{
${ }^{3}$ La Mancomunidad, creada en 1993, tiene entre sus funciones la promoción económica en general y específicamente la promoción turística del territorio, entre otras. Está formada por todos los municipios de Els Ports (Morella, Cinctorres, Forcall, Villores, Olocau, Vallibona, Portell, Todolella, Castellfort, Ares del Maestrat, Sorita, Palanques y Herbers), además de la Pobla de Benifassà y Castell de Cabres (Baix Maestrat); y Ares del Maestre y Vilafranca (Alt Maestrat). En 2011 la mayor parte de los municipios de Els Ports gobernados por el PP (Portell, Todolella, Castellfort, Ares del Maestrat, Sorita, Palanques i Herbers) formaron el Consorci de Pobles Menuts de Els Ports, que apenas ha tenido actividad.
} 
sectores, como el medio ambiente, urbanismo, educación, etc., y también, como en el caso que estudiamos, el turismo. En el caso concreto de la cartografía, nos encontramos con la situación que cada una de las administraciones produce su propia cartografía, que responde a su territorio y/o a sus políticas turísticas.

\subsection{Entes "transfronterizos"}

No todas las estructuras responden a la lógica de los diferentes niveles políticoadministrativos. Encontramos en el mismo territorio un ente local que reúne municipios de las tres comunidades. La mancomunidad de la Taula del Sénia es la única en España que a día de hoy agrupa municipios de tres comunidades autónomas ${ }^{4}$. Creada en 2005 ha tenido entre sus objetivos la mejora de las infraestructuras y comunicaciones entre los municipios del territorio y la coordinación entre las administraciones para mejorar las condiciones del territorio y conseguir inversiones. En los últimos años se ha centrado en la defensa del patrimonio, especialmente en lo que se refiere al aceite y los olivos milenarios, a través de la Associació Territori del Sénia.

Figuras 2 y 3. Taula del Sénia (izquierda) y Diócesis de Tortosa (derecha).
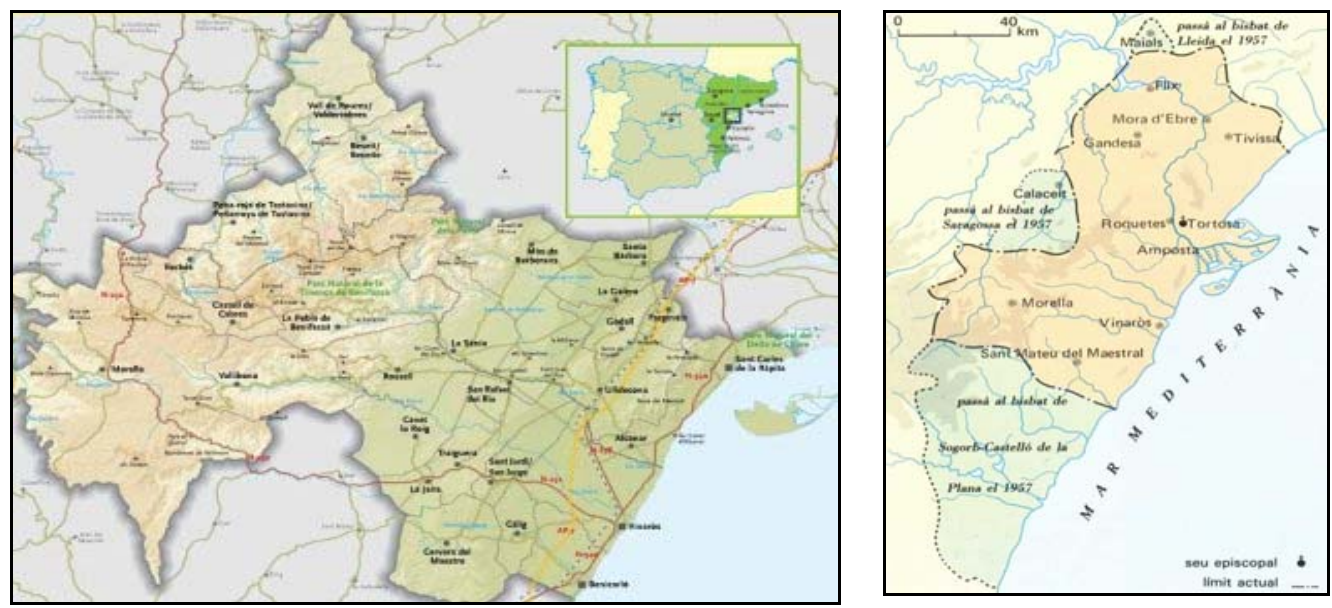

Fuente: Taula del Sénia ${ }^{5}$ (izquierda) y Enciclopedia Catalana (derecha).

${ }^{4}$ La mancomunidad está formada por 27 municipios (15 valencianos: Benicarló, Càlig, Canet lo Roig, Castell de Cabres, Cervera del Maestre, Herbés, la Jana, Morella, la Pobla de Benifassà, Rossell, San Rafael del Río, Sant Jordi, Traiguera, Vallibona y Vinaròs), (9 catalanes: Alcanar, Freginals, la Galera, Godall, Mas de Barberans, Sant Carles de la Ràpita, Santa Bàrbara, la Sénia y Ulldecona) (3 aragoneses: Beceite, Peñarroya de Tastavins y Valderrobres).

${ }^{5}$ Disponible: http://www.tauladelsenia.org 
La existencia de estructuras públicas no hace más que responder a la propia configuración del territorio, rótula o encrucijada entre las tres CCAA, que ha tenido históricamente una fuerte conexión. Un ejemplo de ello es la propia división eclesiástica. La Diócesis de Tortosa - como vemos en la figura 3- engloba todos los municipios del norte de Castellón y sur de Tarragona. También incluía hasta 1957 buena parte de los municipios aragoneses de Matarranya limítrofes con Cataluña (Arenys de Lledó, Calaceite, Cretas y Lledó), hoy en día pertenecientes -como la mayoría de los municipios de la comarca- a la archidiócesis de Zaragoza.

Otra estructura pública ocupa parte del territorio en la encrucijada de las tres comunidades, como es la Reserva Nacional de Caza de Ports de Tortosa Beseit, en parte de los términos municipales de Alfara de Carles, Roquetes, Tortosa, Mas de Barberans, la Sénia, Arnes y Horta de Sant Joan en Cataluña, Beseit en Aragón y la Pobla de Benifassà en la Comunidad Valenciana. La Reserva fue creada en 1966 y ocupa una extensión de 28.587,17 hectáreas. Está gestionada conjuntamente por las consejerías responsables de las tres comunidades autónomas.

\subsection{La división del macizo: diferentes niveles de protección}

Un elemento fundamental en el análisis de la arquitectura institucional del territorio se refiere a la propia protección ambiental del macizo. Como ya hemos avanzado al principio de este apartado, buena parte de la regulación sectorial tiene un componente de interiorización autonómica importante. La protección ambiental es una de ellas, y ello tiene un reflejo importante en la articulación ambiental de Els Ports, que presenta tres niveles de protección ambiental muy diferentes entre sí.

En primer lugar, la parte catalana del macizo constituye el Parc Natural dels Ports, creado el año 2001, con el Decreto 160/2001, de 12 de junio, de declaración del Parque Natural de Els Ports y de la Reserva Natural Parcial de les Fagedes de Els Ports. Su protección se ha ido incrementando con los años ${ }^{6}$, en contraposición a una regulación menor en el resto de comunidades. Así, en la parte valenciana del macizo -incluyendo los municipios de la pobla de Benifassà, Vallibona y parte de Rossell-, en un nivel inferior de protección, encontramos el Parc natural de la Tinença de Benifassà, declarado por el Decreto 70/2006 de 19 de mayo de la Generalitat Valenciana. El propio legislador valenciano reconoce que "Paisajística y

${ }^{6} \mathrm{La}$ protección del parque se ha incrementado con los años a través de la Orden MAH/481/2006, de 15 de septiembre, el Refugi de Fauna Salvatge dels Estrets d'Arnes (2006), la designación del parque como Zona de Especial Protección para las Aves (ZEPA) y su incorporación a la red ecológica europea Natura 2000 (2006), la adopción Lugar de Importacia Comunitaria (LIC) por Decisión de la Comisión Europea (2008), la incorporación de buena parte del parque en la declaración de las Terres de l'Ebre como Reserva de la Biosfera por UNESCO (2013) y la declaración del parque como Zona Especial de Conservación (ZEC) (2014). 
geomorfológicamente, la Tinença forma parte del gran macizo de els Ports de Beseit que comparten las comunidades autónomas de Aragón, Cataluña y Valencia" ${ }^{7}$, aunque su regulación, obviamente, sólo puede abarcar el territorio valenciano. Finalmente, la parte aragonesa está inmersa actualmente en un proceso de intento de creación del Parque Natural de Los Puertos de Beceite ${ }^{8}$, en un claro caso de choque de intereses entre las presiones para la protección ambiental y las de sectores económicos para impedirlo o minimizar el alcance. Parece claro que por coherencia normativa y de gestión del macizo también la parte aragonesa debería contar con protección ambiental ${ }^{9}$, aunque a día de hoy no se ha avanzado en dicho sentido.

\section{La promoción del turismo en Els Ports}

\subsection{La competencia en turismo: divergencia y diversidad}

No es lugar aquí para entrar en la regulación jurídica del turismo, aunque sí conviene precisar que la materia de turismo es una competencia exclusiva autonómica (PérezGuerra y Ceballos-Martín, 2009: 468). De acuerdo con el art. 148.1.18 de la Constitución Española, la "promoción y ordenación del turismo en su ámbito territorial" puede ser asumida por las comunidades autónomas. De hecho, así ha sucedido tanto en Cataluña (art. 171 EAC) como Aragón (art. 71.51 EAA). En ambos casos se trata de una competencia que incluye la ordenación del sector y la promoción turística. En el caso aragonés, además, el art. 23 de la Ley comarcal atribuye el fomento del turismo a las comarcas. Las comarcas catalanas no lo tienen atribuido en la ley comarcal, pero sí en la Ley 13/2002, de 21 de junio, de turismo de Catalunya

${ }^{7}$ Orden de 29 de abril de 2008, de la Conselleria de Medio Ambiente, Agua, Urbanismo y Vivienda, por la que se acuerda iniciar el procedimiento de elaboración y aprobación del Plan Rector de Uso y Gestión del Parque Natural de la Tinença de Benifassà.

8 "Las Cortes de Aragón instan a DGA a crear el Parque Natural de Los Puertos de Beceite", La Comarca, 16 de junio de 2017 (Accesible en https://www.lacomarca.net/las-cortes-dearagon-instan-a-dga-a-crear-el-parque-natural-de-los-puertos-de-beceite/); "DGA preguntará por la creación del Parque Natural en el Matarraña", La Comarca, 28 de mayo de 2018 (Accesible en https://www.lacomarca.net/dga-preguntara-por-la-creacion-del-parque-naturalen-el-matarrana/).

${ }^{9}$ En este sentido, el Consejo de Protección de la Naturaleza de Aragón (CPNA) afirmaba que "Se hace necesaria, por tanto, una protección de estos lugares para evitar la degradación de sus valores, además de dotar al ámbito geográfico de una coherencia normativa y de gestión respecto a los espacios que ya se encuentran protegidos con esta misma categoría en las Comunidades vecinas de Cataluña y Valencia." Por tanto, el consejo proponía priorizar su declaración como espacio natural protegido en la categoría de Parque Natural. Consejo de Protección de la Naturaleza de Aragón (CPNA), Dictamen del Pleno, de 8 de noviembre de 2012. 
(art. 70). La intervención de la administración en la promoción de actividades turísticas se traduce generalmente en la promoción turística del municipio o de ofertas turísticas determinadas de ámbito supramunicipal. Todas las Administraciones prestan servicios relacionados con la promoción turística. También las comarcas, de carácter supramunicipal, y en general conectados con una oferta de ocio que se centra en un activo del territorio de tipo ambiental.

También los municipios, según el art. $25.2 \mathrm{~m}$ ) LBRL, pueden ejercer competencias en materia de turismo, de acuerdo con el marco establecido por las leyes estatal y autonómicas. En este sentido, la Ley 13/2002, de 21 de junio, de turismo de Catalunya, prevé la posibilidad de descentralizar competencias de turismo en favor de municipios, consejos comarcales y diputaciones. No existen problemas relevantes en lo que se refiere disposiciones contradictorias con la Ley 3/1998, de 21 de mayo, de Turismo de la Comunitat Valenciana y el Decreto Legislativo 1/2016, de 26 de julio, del Gobierno de Aragón, por el que se aprueba el texto refundido de la Ley del Turismo de Aragón. El problema más relevante lo encontramos en la completa descoordinación -o más bien desconexión- con las comunidades autónomas vecinas, por lo que la promoción del turismo en este territorio no parece obedecer a razones de eficacia y eficiencia, sino a iniciativas individuales y desconectadas, no sólo entre comunidades autónomas sino también entre las administraciones de cada una de ellas.

\subsection{Escenario multinivel y falta de cooperación entre administraciones}

Ante la falta de una estrategia común, y como hemos visto la posibilidad de que cada una de las administraciones promocione por separado sus activos turísticos, la realidad nos muestra una situación compleja en la que cada uno de los actores actúa por su cuenta. La Tabla 1 muestra la realidad de la fragmentación de la oferta turística, y como las estrategias diferenciadas se expresan cartográficamente. Aun así debemos volver a la arquitectura institucional ya descrita para ver qué administraciones prestan servicios de promoción turística en el territorio. Es importante hacer este ejercicio, en primer lugar, porque, aunque existen iniciativas privadas de promoción turística, el territorio es fuertemente dependiente de la iniciativa pública. En segundo lugar, porque observar conjuntamente los servicios que se prestan nos muestra claramente la necesidad de la cooperación, por cuestiones de eficacia, eficiencia y economía.

Un caso puede ayudarnos a poner de manifiesto la falta de una política común en intereses compartidos. El Patronato de Turismo de la Diputación de Tarragona, conjuntamente con los consejos comarcales de Terra Alta y Baix Ebre han publicado el Catálogo de la Vía Verde del Valle de Zafán, que como se explica "es una ruta turística que transcurre por la antigua vía férrea del Valle de Zafán donde, atendido al interés del gobierno de Aragón por tener puerto de mar para explotar sus productos, 
construyeron un trazado ferroviario que pretendía unir el municipio de la Puebla de Híjar con Tortosa." 10

Tabla 1. Promoción turística en los diferentes niveles político-administrativos.

\begin{tabular}{|c|c|c|c|}
\hline Tipo de ente & Catalunya & Aragón & Comunitat Valenciana \\
\hline $\begin{array}{l}\text { Administración } \\
\text { autonómica }\end{array}$ & $\begin{array}{c}\text { Agència Catalana de Turisme } \\
\text { Generalitat (Turisme) }\end{array}$ & $\begin{array}{c}\text { Diputación General de } \\
\text { Aragón (Dirección General } \\
\text { de Turismo) }\end{array}$ & $\begin{array}{c}\text { Agència Valenciana del } \\
\text { Turisme } \\
\text { Centro de Turismo e } \\
\text { Innovación Mediterráneo Rural } \\
\text { Els Ports }\end{array}$ \\
\hline $\begin{array}{l}\text { Diputaciones } \\
\text { provinciales }\end{array}$ & $\begin{array}{c}\text { Patronato de Turismo } \\
\text { (Diputación de Tarragona) }\end{array}$ & $\begin{array}{c}\text { Turismo Diputación de } \\
\text { Teruel (Teruel Versión } \\
\text { Original) }\end{array}$ & $\begin{array}{l}\text { Patronato Provincial de } \\
\text { Turismo de Castellón }\end{array}$ \\
\hline Comarcas & $\begin{array}{l}\text { Terra Alta: Paradís rural } \\
\text { Montsià (Sitio web, } \\
\text { información parcial del área } \\
\text { dels Ports) } \\
\text { Baix Ebre (Sitio web, con } \\
\text { información abundante de la } \\
\text { Vía Verde) }\end{array}$ & $\begin{array}{l}\text { Comarca Matarranya: } \\
\text { Matarranya Turismo }\end{array}$ & $\begin{array}{c}\text { Mancomunidad Comarcal Els } \\
\text { Ports: }\end{array}$ \\
\hline Municipios & $\begin{array}{c}\text { Oficinas de turismo en Alfara } \\
\text { de Carles, Arnes, Horta de Sant } \\
\text { Joan, la Sénia, Mas de } \\
\text { Barberans, Paüls, Prat de } \\
\text { Comte, Roquetes y Tortosa }\end{array}$ & $\begin{array}{l}\text { Oficinas de Turismo en } \\
\text { Calaceite, la Fresneda, } \\
\text { Monroyo, Peñarroya de } \\
\text { Tastavins y Valderrobres. }\end{array}$ & $\begin{array}{c}\text { Oficinas de Turismo en } \\
\text { Benassal, Benicarló, Catí, } \\
\text { Cinctorres, Forcall, Tinença de } \\
\text { Benifassà, Morella, Traiguera y } \\
\text { Vinaròs }\end{array}$ \\
\hline $\begin{array}{c}\text { Entes } \\
\text { asociativos }\end{array}$ & \multicolumn{3}{|c|}{ Mancomunidad Taula del Sénia (Olivos milenarios) } \\
\hline
\end{tabular}

Fuente: Elaboración propia.

El propio título del apartado explicativo se titula "La unión de las Terres de l'Ebre con Aragón", aunque el recorrido, que arranca en Tortosa, finaliza en Arnes. No entra pues en territorio aragonés, a pesar de la denominación de la vía, y no da ninguna información de la vía una vez abandona territorio catalán. El mapa (pág. 3), también finaliza en el municipio catalán de Arnes. La misma orientación tiene la publicidad Escapadas e itinerarios por la Vía Verde ${ }^{11}$ : ninguno de ellos entra en territorio

${ }^{10}$ La Via Verde, Patronato de Turismo de la Diputación de Tarragona (accessible en http://baixebre.cat/sites/default/files/pagina/277/documents/via-verda-castellano.pdf)

${ }^{11}$ Escapadas e itinerarios por la Vía Verde. Bajo Ebro. Terra Alta. Consejos Comarcales de Baix Ebre y $\quad$ Terra Alta (Accesible en http://baixebre.cat/sites/default/files/pagina/277/documents/itineraris-viaverda-esp.pdf ) 
aragonés (el mapa de la pág. 27 es muy clarificador al respecto), y la información sobre empresas que operan en la vía son todas catalanas. Por otro lado, la Diputación de Teruel promociona la sección aragonesa de la Vía Verde Val de Zafán, desde Lledó a Valjunquera, dentro de la comarca de Matarranya. En el mapa que acompaña al material promocional podemos comprobar también que sólo se incluye información referente a Matarranya ${ }^{12}$.

La falta de cooperación no es exclusiva de las políticas turísticas, sino generalizada en casi todos los sectores -quizás la cooperación en materia educativa, sanitaria o en extinción de incendios han sido la que han tenido más incidencia-. Diferentes autores han denunciado la ineficacia de los instrumentos de colaboración entre CCAA ya que apenas se han aprobado convenios y acuerdos (Aja, 2014: 212), llegando a afirmar que la cooperación horizontal ha sido casi inexistente (García Morales, 2006). Tal y como se ha puesto de relieve, el fenómeno cooperativo es una realidad extraordinariamente compleja, y aparte de la norma tiene un protagonismo muy relevante la lógica de la decisión política (González García, 2016: 163).

\subsection{Una promoción turística diferenciadora y segregadora}

El hecho de encontrarnos con políticas separadas de promoción turística también se traslada a la cartografía, uno de los principales instrumentos de configuración de la oferta. La visión política influye de forma determinante en la elaboración de mapas, y el caso de la promoción turística es un claro ejemplo de ello. El turismo se convierte no solamente en una actividad relevante para el territorio -especialmente en aquellos con una economía precaria como el que estudiamos en el presente artículo-, sino también en un instrumento que los poderes públicos utilizan para su afirmación territorial. Las políticas turísticas pretenden atraer visitantes, y con ello incrementar la actividad económica, pero también construyen un relato -histórico, cultural, socialde afirmación propia y diferenciación respecto a los territorios vecinos. No sólo en los mapas, sino también en la propia promoción (folletos informativos, páginas web o en

12 Via verde Val de Zafán Comarca del Matarranya (Accesible en.http://www.teruelversionoriginal.es/turismo/wpcontent/uploads/2016/02/Via_Verde_Matar ranya.pdf). En el resto de material promocional de "Teruel Versión Original" vemos que la cartografía sigue un patrón similar, tanto en referencia con los senderos (Sendero G-8, accesible en http:/www.teruelversionoriginal.es/turismo/wpcontent/uploads/2016/02/Senderos_Matarranya.pdf) como con los paseos y excursiones. Se da la curiosidad en el material "Paseos y excursiones" editado por la comarca del Matarranya sólo se incluyen las poblaciones aragonesas próximas a la comarca, pero no las catalanas o valencianas, a pesar de que sí se han incluido las carreteras (Accesible en http://www.teruelversionoriginal.es/turismo/wpcontent/uploads/2016/02/Paseos_Excursiones_ Matarranya.pdf). 
el propio texto de los productos cartográficos) el texto incide en esta idea, de forma que el relato propio excluye al otro.

Veamos algunos ejemplos muy concretos al respecto. Uno de ellos lo forma la cartografía del Parque Natural dels Ports (Figura 4), realizado por la Generalitat de Catalunya. Aunque aparecen indicados los principales municipios aragoneses y valencianos, no se indica en ningún momento que pertenezcan a otras comunidades autónomas. Por otra parte, el texto que aparece como subtítulo del mapa aclara que el público puede acceder al parque mediante tres "vías": el Baix Ebre, el Montsià y la Terra Alta -todas ellas comarcas catalanas, aunque el acceso al Parque también puede realizarse, lógicamente, a través de los municipios aragoneses y valencianos. El relato, por tanto, incide en segregar el territorio para adaptarlo al mapa institucional, y en este sentido la cartografía es un poderoso instrumento para lograrlo.

Por otra parte, la composición cartográfica de la Figura 5 nos muestra de forma muy explícita la concepción que traslada la promoción turística de la comarca del Matarranya. En este caso, vemos algunos de los problemas habituales en cartografía, como lo es el efecto isla ${ }^{13}$ : la comunidad autónoma de Aragón, en la segunda imagen, se encuentra rodeada de un espacio de tonalidades ocres que representa el mar en la primera secuencia (donde aparece el continente europeo). Este error se repite hasta la tercera imagen, donde la comarca del Matarranya entera aparece como si de una isla se tratara, sin incluir las comarcas catalanas y valencianas.

Finalmente, la Figura 6 nos presenta el municipio de Beceite y, adicionalmente, una serie de excursiones para realizar a través de su término. Observamos que el efecto isla vuelve a repetirse. Esta vez el "error" es aún más pronunciado: se proponen una serie de excursiones, una de las cuales se adentra en el Parque Natural de Els Ports, pero sin ninguna referencia geográfica aceptable: fondo blanco y ausencia de topónimos relevantes. Beceite queda, otra vez, como un territorio separado del límite administrativo con Cataluña. El sendero que logra atravesar sus límites conduce, pues, a una tierra incógnita.

Estos tres mapas no representan casos aislados, sino que son habituales en el territorio que estudiamos. Cada uno de estos mapas producidos con finalidades turísticos en el área analizada tiene una visión centrada en el activo a promocionar, de forma individualizada, y una visión institucional. Dos visiones que coexisten con una "desconexión" de los territorios vecinos, que en la representación cartográfica, simplemente, no existen. La visión es, por tanto, supramunicipal -comunidad, provincia, comarca- y centrada en la propia oferta, sin ofrecer vías sinérgicas a los territorios vecinos.

${ }^{13}$ El efecto isla es el resultado de cartografiar un espacio sin representar debidamente los territorios contiguos. Es por este motivo que el espacio representado parece una "isla", pues queda "aislado" de cualquier otro territorio limítrofe. 
Figura 4. Cartografía oficial del Parque Natural de Els Ports (Generalitat de Catalunya).

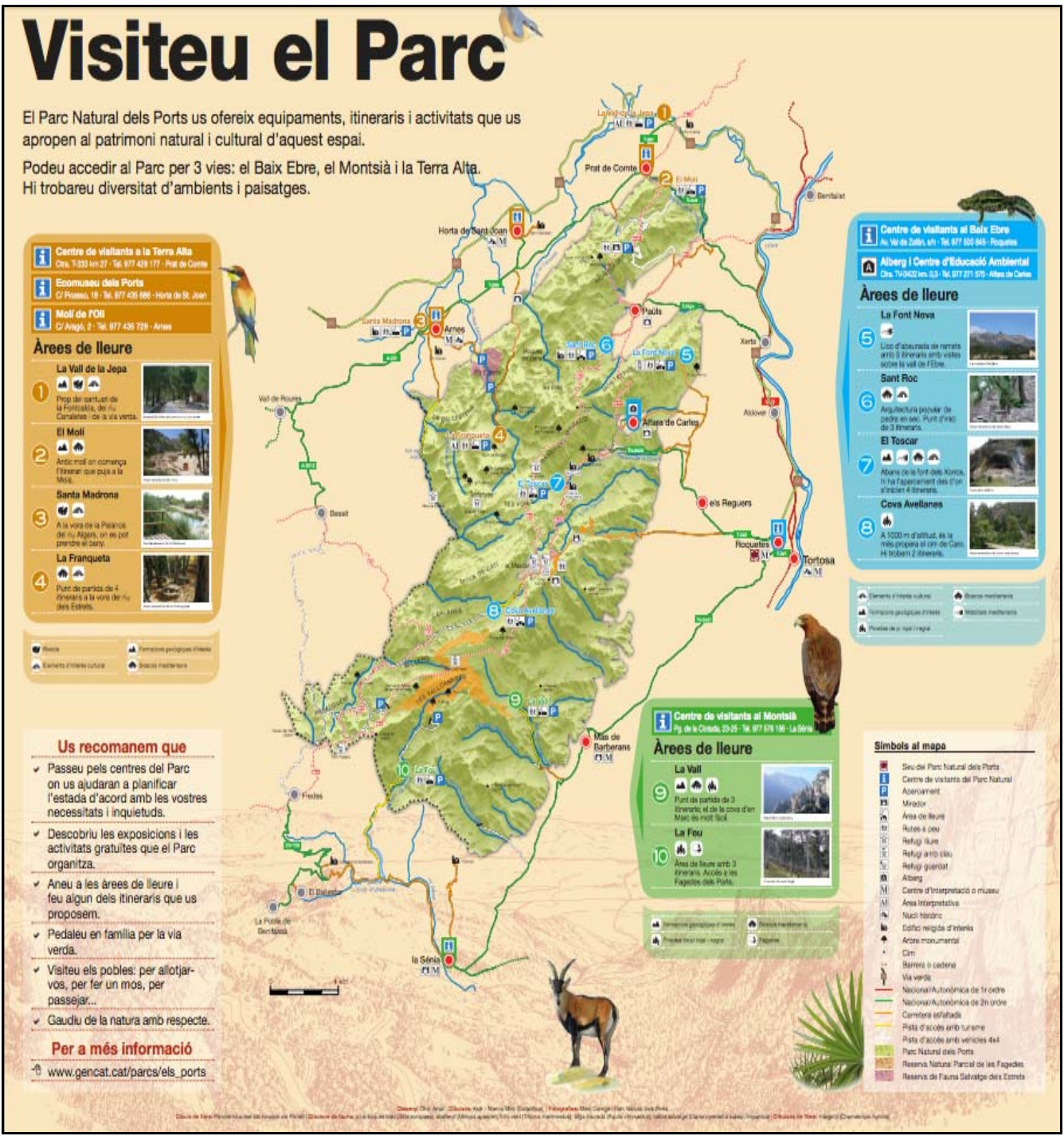

Fuente: Generalitat de Catalunya ${ }^{14}$

${ }^{14}$ http://www.viulebre.com/downloads/Mapa_PN_Ports.pdf (último acceso el 26 de marzo de 2020). 
Figura 5. Cartografía de promoción turística de la comarca del Matarranya (Aragón).

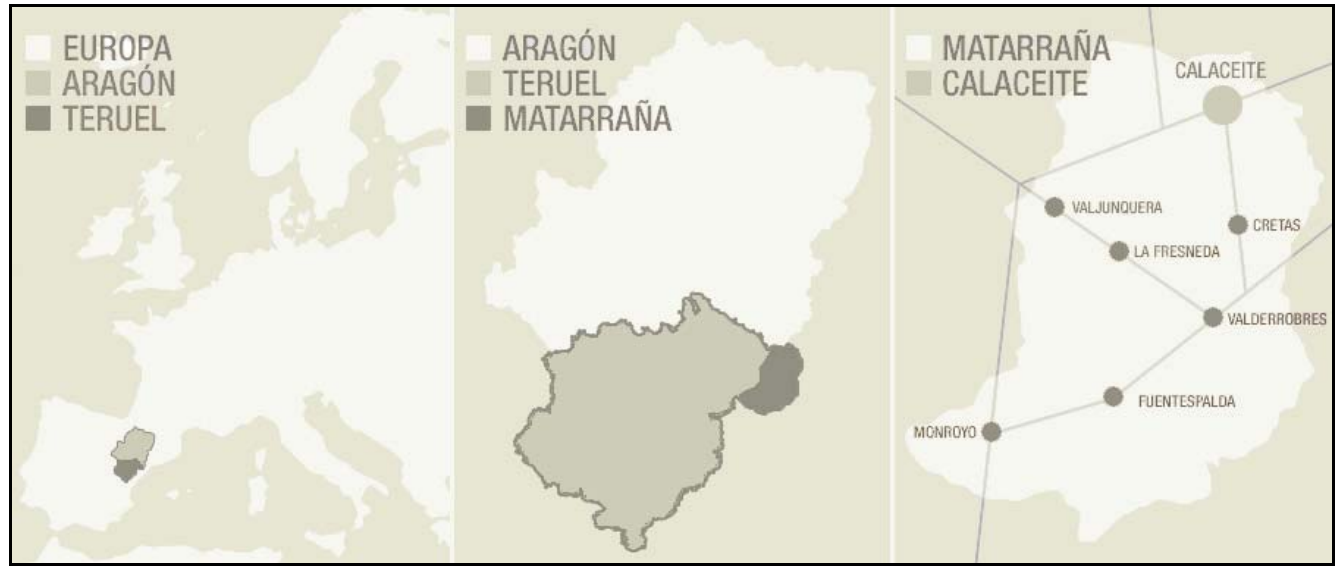

Fuente: Matarranya Turismo ${ }^{15}$

Figura 6. Cartografía del Ayuntamiento de Beceite (Aragón).

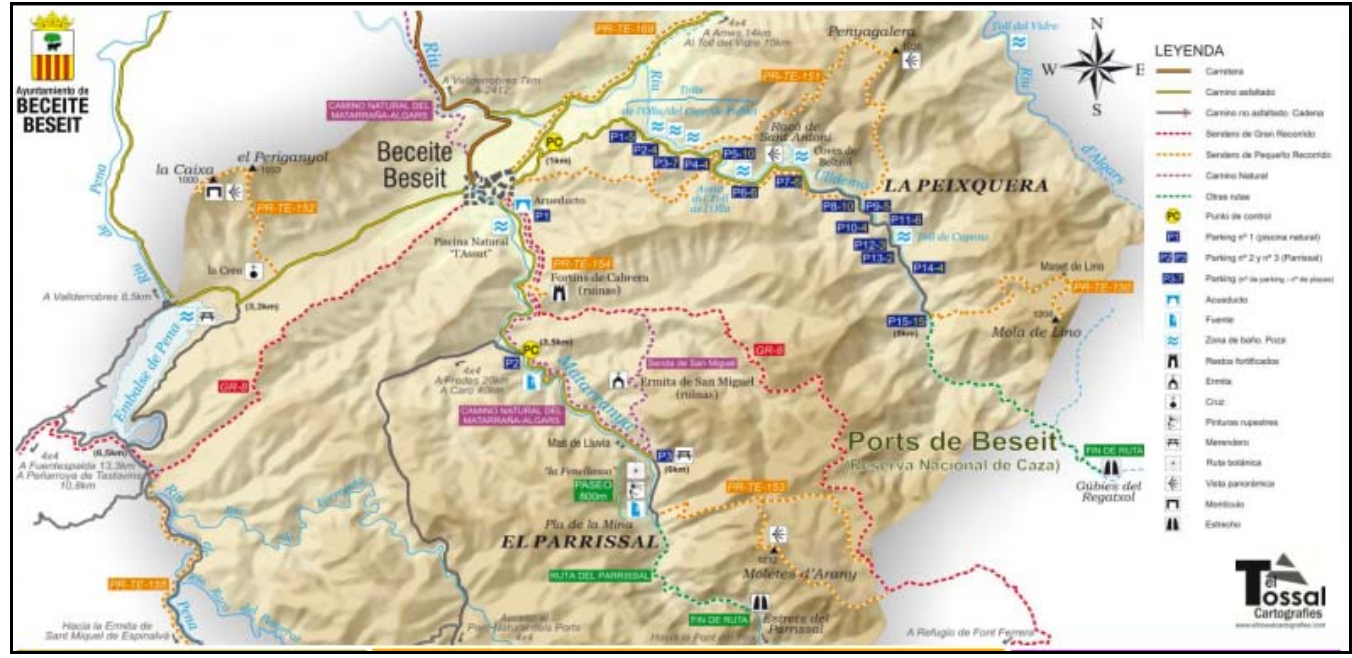

Fuente: Ayuntamiento de Beceite ${ }^{16}$

${ }^{15} \mathrm{http}: / /$ matarranyaturismo.es/matarranya/ (último acceso el 26 de marzo de 2020). Una representación similar se encuentra en http://matarranyaturismo.es/folletos/

${ }^{16} \mathrm{http}: / / w w w . b e c e i t e . e s / w p-c o n t e n t / u p l o a d s /$ sites/117/2018/04/BECEITE.-Folleto-Excursiones.2018.pdf (último acceso el 26 de marzo de 2020). 


\subsection{La necesidad de cooperar: el mapa como oportunidad}

La cooperación en ámbitos de frontera es una opción que se ha demostrado como necesaria, especialmente en territorios que presentan una condición periférica. En nuestro caso, es especialmente relevante en casi todos los municipios fronterizos que comparten el territorio del macizo de Els Ports. En un estudio reciente sobre los municipios de frontera interautonómica se ha puesto en evidencia la inexistencia de políticas "transfronterizas" en materia de turismo en los municipios adyacentes al límite entre Cataluña y Aragón, donde sólo un 11,6\% afirma haber realizado algún tipo de cooperación con municipios de la otra comunidad autónoma, aunque un $60,9 \%$ estima que debería existir mayor cooperación (Galindo Caldés, 2018b). En el tramo correspondiente a nuestro ámbito de estudio (comarcas de Matarranya y Terra Alta), un $25 \%$ de los municipios afirma haber cooperado en materia de turismo, mientras que un $68,8 \%$ estima que debería existir una mayor cooperación en este sector $^{17}$, de forma casi unánime entre los municipios aragoneses. Los datos son más elevados, por dos razones. En primer lugar, se ha cooperado más, precisamente a través del proyecto Tres Territoris, que exponemos más adelante. Por otro lado, parece existir una mayor concienciación de la necesidad de cooperar, en un ámbito geográfico especialmente periférico de sus capitales provinciales (Teruel y Tarragona).

El ejemplo de la Mancomunidad de la Taula del Sénia pone de manifiesto la voluntad de cooperar y aunar esfuerzos en un territorio que presenta los problemas ya expuestos de complejidad institucional y dificultades para articular soluciones para el conjunto del territorio. Se trata de una experiencia consolidada y que ha superado dificultades por el contexto político, siendo bien valorada por los municipios participantes. En este sentido, la mancomunidad ha sabido visualizar el territorio en su conjunto, utilizando el río Sénia como eje articulador del territorio. El territorio Sénia pretende ser un lugar de encuentro para afrontar problemas comunes -olivos, caminos- desde una perspectiva global.

La existencia de los problemas ya mencionados, así como la asunción de la necesidad de cooperar llevó a los entes supramunicipales de parte del territorio comarcas de Matarranya, Terra Alta y Mancomunidad Comarcal Els Ports- a poner en funcionamiento el proyecto Tres Territoris. Una mateixa terra (Tres Territorios. Una misma tierra). Se trata de un acuerdo muy limitado, centrado en la puesta en

${ }^{17}$ Los datos, correspondientes a 11 municipios de la comarca de Matarranya (Arens de Lledó, Beceite, Calaceite, Cretas, Lledó, Valderrobres) y Terra Alta (Arnes, Batea, Caseres, Horta de Sant Joan, La Pobla de Massaluca) fueron respondidos por los alcaldes y/o los secretarios municipales de todos los municipios. Los 14 cuestionarios fueron respondidos por 10 alcaldes (todos excepto el de Caseres) y 6 secretarios municipales (de todos los municipios excepto La Pobla de Massaluca, Beceite y Valderrobres). Los cuestonarios se cumplimentaron en enero de 2017. 
funcionamiento de un sitio web (www.3territoris.org). Tal y como se afirma en el propio web, "En épocas pasadas, los tres territorios estaban unidos por lazos comerciales, con rutas que comenzaban en el interior y llegaban hasta el Mediterráneo y viceversa. El intercambio comercial se producía en las ferias, que suponían el punto de encuentro entre sus habitantes, quienes compartían tradiciones, gastronomía y, en definitiva, una forma de vida. En la actualidad, los tres territorios siguen unidos y tienen mucho que ofrecer a quienes vienen atraídos por la autenticidad de las tierras de frontera." Su objeto es por tanto turístico, buscando ofrecer una oferta única, "de frontera", aunando esfuerzos de promoción de los activos turísticos de cada una de las comarcas.

El proyecto tiene dos elementos muy positivos y singulares, que analizamos a continuación, como son la denominación y el mapa. Ambos representan un esfuerzo de cooperación y de estrategia conjunta, que pueden ser el inicio de una colaboración en otros sectores:

1. Denominación. Cualquier denominación suele ser controvertida, especialmente cuando de lo que se trata es aunar varios territorios que internamente tienen como objetivo cohesionarse internamente. De esta forma, encontramos nombres históricos, como el Maestrazgo (Maestrat), pero otros que utilizan un elemento geográfico central en tu territorio como base para su denominación, como Montsià, Matarranya, Baix Ebre o Terra Alta. Los elementos geográficos centran la comarca y la cohesionan internamente, dejando al macizo dels Ports $-\mathrm{y}$ a todos los municipios en los que se divide administrativamente ${ }^{18}$ - en una situación periférica respecto a sus centros comarcales. Sólo la comarca de Els Ports adopta la denominación del macizo como propia, aunque sólo ocupa una parte menor de él.

La posibilidad de utilizar la denominación de Els Ports ha sido objeto de discusión por la diferente denominación (Ports de Tortosa, Puertos de Beceite, els Ports). Hay un cierto consenso en la utilización de la denominación como "Massís dels Ports" (macizo de Els Ports), aunque en el proyecto aragonés de Parque Natural se le sigue denominando "Puertos de Beceite", a pesar de que sólo una parte del macizo pertenece al municipio. La denominación del territorio como "Els Ports", a pesar de parecer pacífica, no lo es. Como hemos dicho, la utilización de un elemento geográfico para denominar un territorio es muy habitual. Hemos visto la relativa implantación de la denominación "Territori del Sénia" en un espacio muy cercano y parcialmente coincidente. La utilización del río Sénia para denominar el territorio interautonómico a ambos lados del cauce fluvial ha generado consenso. La implantación de la mancomunidad ya descrita sin duda ha ayudado a consolidar la denominación.

${ }^{18}$ Los municipios con territorio en el macizo son Tortosa, Roquetes, Alfara de Carles y Paüls (Baix Ebre); Horta de Sant Joan, Pinell de Brai y Arnes (Terra Alta); Mas de Barberans y la Sénia (Montsià); Pobla de Benifassà, Rossell (núcleo de Bel) y Castell de Cabres (Baix Maestrat); Vallibona (Els Ports); Beceite y Valderrobres (Matarranya) 
En nuestro caso, en el marco del proyecto de colaboración se ha optado por una denominación neutra y descriptiva, que simplemente significa la unión de tres territorios. Tres Territoris simboliza la unidad de las tres comarcas (Terra Alta, Matarranya y Els Ports), y también de las tres comunidades autónomas. La denominación Tres Territoris significa unión, pero también afirma la unidad interna de cada una de las partes. Las comarcas -y las comunidades- son las protagonistas del acuerdo. No hay disolución de las partes en un territorio común, como de hecho hace la denominación "Territori del Sénia", en la que el eje es el territorio, basado en los municipios que lo componen. Lo que es común en ambas denominaciones es la condición de frontera, de encrucijada (cruïlla), de punto de encuentro.

2. La visualización del territorio: el mapa de Tres Territoris. La construcción del mapa -que vemos a continuación- de los Tres Territoris tiene una importancia fundamental. Una primera es muy evidente, respecto a la que hemos mostrado anteriormente sobre turismo en Matarranya, y es que agrupa los tres territorios e introduce diferentes escalas. Sigue teniendo algunos defectos, como el hecho de que siguen siendo mapas isla y que el ámbito local está ausente, pero supone un avance en lo que se refiere a crear un espacio supralocal y transfronterizo, que permite identificarlo.

3. Medios de promoción: sitio web y "Qué hacer". Ya existía, desde 2016, una publicación semestral de difusión turística de los tres territorios, que se distribuía en los municipios costeros en primavera y verano. La publicación, Qué Hacer. 3 territorios por descubrir se ha seguido editando y distribuyendo hasta el día de hoy. Incluye tanto el mapa como reportajes de los diferentes municipios, con el objetivo de atraer visitantes que pasan sus vacaciones en la costa. El sitio web de Tres Territoris, publicado por vez primera en febrero de 2017, tiene el objetivo de ser el medio principal de promoción conjunta del territorio. No obstante, no se ha actualizado el blog desde abril de 2017 ni la agenda de actividades desde diciembre de 2017.

4. El camino de los Tres Territoris. Uno de los proyectos relacionados con la iniciativa era la creación del Camí Natural dels Tres Territoris, que según se expuso durante la presentación del web "empezará en la Terra Alta, acabará en Morella y recorrerá todo el Matarranya", convirtiéndose "en un punto de atracción turística de nuestros territorios"19. El camino se impulsará a través de la Associació dels 3 Territoris, constituida en diciembre de 2017, aunque por el momento no se ha avanzado en este aspecto.

19 "Naix 3territoris.org, el portal de promoció de la Terra Alta, el Matarranya i Morella", Ràdio Matarranya (Comarquesnord), 28 de febrero de 2017 [Accesible en http://comarquesnord.cat/radiomatarranya/2017/02/28/naix-3territoris-org-el-portal-depromocio-de-la-terra-alta-el-matarranya-i-morella/) 
Figura 7. Cartografía del proyecto Tres Territoris.

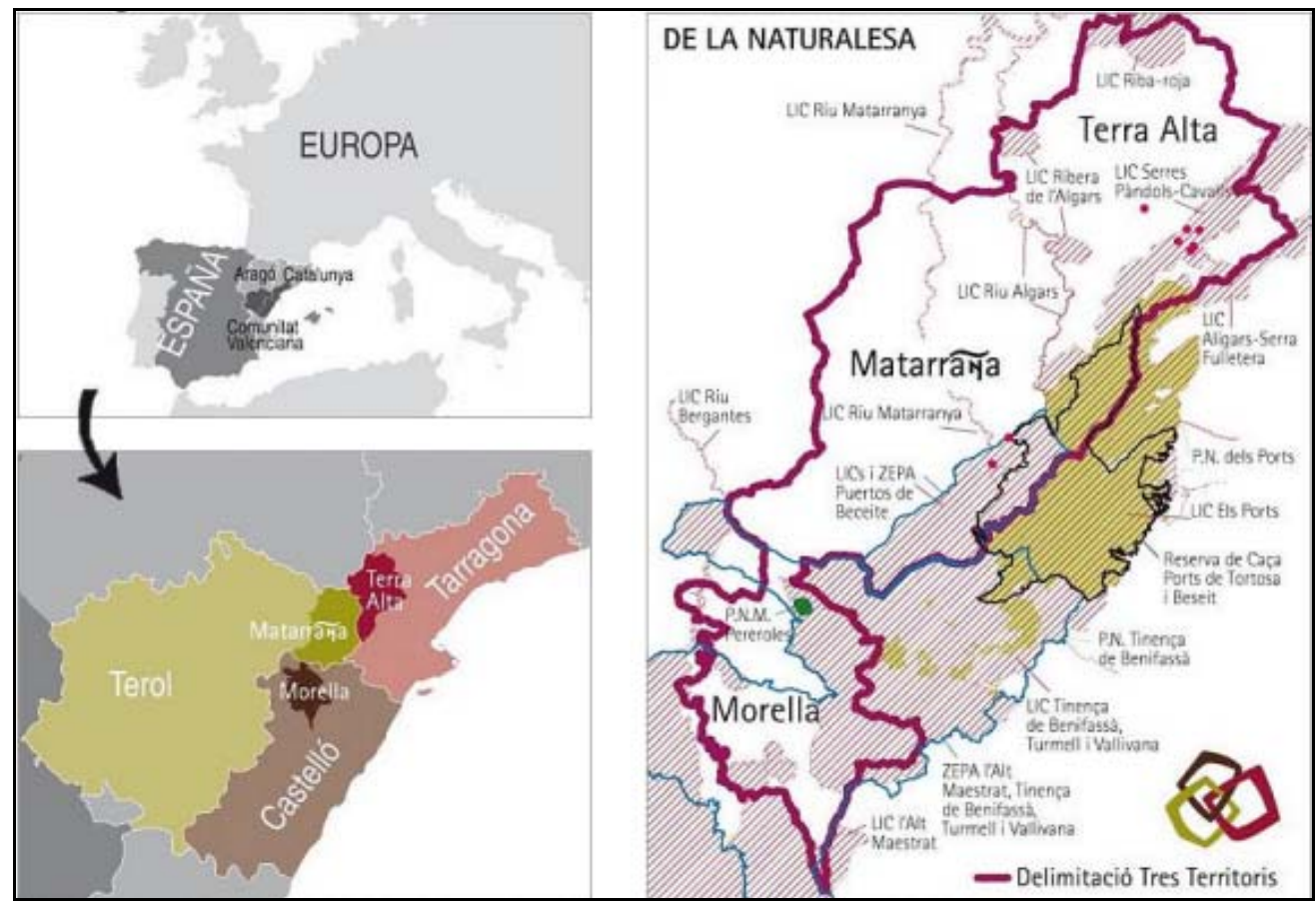

Fuente: Tres Territoris de mateixa terra ${ }^{20}$

\subsection{Las dificultades para articular una fórmula de cooperación}

Consideramos el proyecto Tres Territoris como un caso de éxito. En primer lugar por las dinámicas divergentes que todo entorno fronterizo introduce en la cooperación, y que hay que vencer para construir cualquier proyecto de cooperación. Se abordan además dos elementos que ya hemos identificado como relevantes, como son la denominación -la marca- y el mapa del territorio. No obstante, la iniciativa se ha construido de forma frágil, de forma que su continuidad o abandono depende más de las partes -sujetas al contexto político- que a una planificación a largo plazo. A continuación, describimos de forma muy breve las opciones de articulación y consolidación de que dispone esta iniciativa.

${ }^{20}$ Disponible en: http://www.3territoris.org/es (acceso el 28 de marzo de 2020). 


\subsubsection{Las dinámicas divergentes de promoción turística}

Los agentes en el territorio tienen intereses divergentes a la hora de afrontar sus políticas turísticas, de la misma forma que en el resto de sectores. Como ya se ha avanzado, e ilustramos en el siguiente gráfico, las administraciones supramunicipales tienden a cohesionar sus propios territorios utilizando la implementación de políticas públicas y la prestación de servicios públicos en su propio territorio. De la misma forma sucede con las normas, que cierran el espacio en el que deben aplicarse y por tanto obligan a su cumplimiento por parte de los particulares. Tanto comarcas -donde las hay-, diputaciones y comunidades autónomas llevan a cabo dinámicas que tienen como objeto cohesionar el territorio propio, por oposición al vecino. Por otra parte, las dinámicas del territorio en su conjunto son convergentes, en el sentido de que los lazos culturales, económicos y sociales ejercen una presión para mantener la unidad. El hecho de tratarse de territorios periféricos hace que la cooperación informal sea la opción más racional.

Figura 8. Dinámicas divergentes y convergentes en la cooperación.
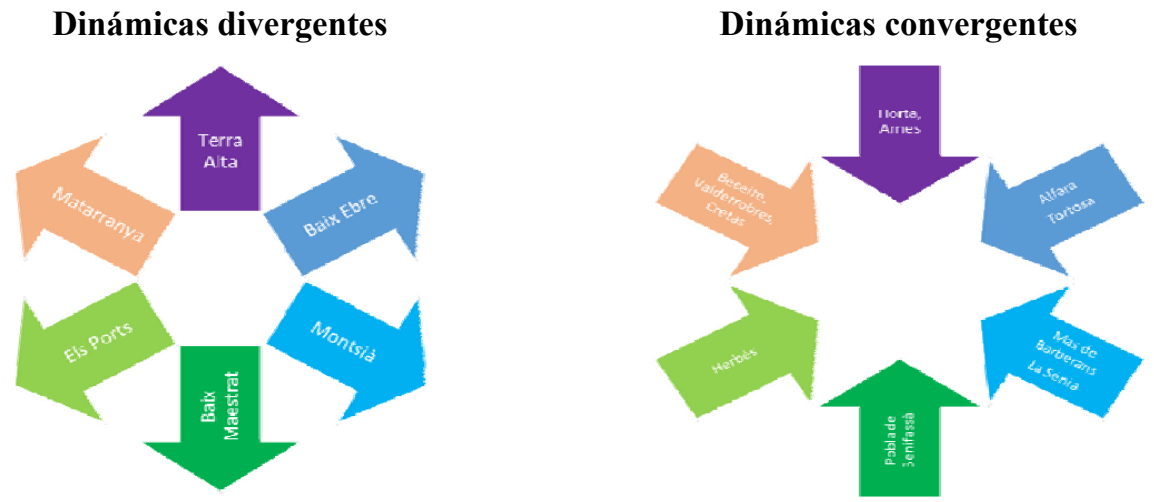

Fuente: Elaboración propia.

Las políticas turísticas son buena prueba de ello, ya que como ya hemos visto tienen por objeto construir un relato del territorio -propio-, individualizado y utilizando la cartografía como instrumento para visualizar esa homogeneidad y cohesión territorial. Afirmamos que el proyecto es un caso de éxito en el sentido que la iniciativa supone un esfuerzo de visión a medio y largo plazo, estratégica y cooperativa. Es también una iniciativa bottom-up, desde los gobiernos locales (comarcales), lo que supone un reto por disponer de recursos limitados y condicionantes de todo tipo. Supone también un claro intento de superar las dinámicas divergentes de promoción turística del territorio, respaldándose en el tejido local-social, económico y cultural- y en los fuertes lazos entre las tres partes. 


\subsubsection{Las opciones: personificadas o no, públicas o de gestión privada}

Desde un punto de vista jurídico existen diversas fórmulas de cooperación que podrían utilizarse en nuestro caso (Tabla 2). Cada una de ellas tiene ventajas en inconvenientes. No entramos en el detalle de cada una de ellas. En el estudio ya citado sobre los municipios de frontera se puede acceder a una sistematización de todas ellas (Vilalta Reixach, 2018). Sí ponemos de manifiesto en el caso analizado que la utilización de una fórmula personificada comporta mayor estabilidad. El caso de la Mancomunidad de la Taula del Sénia es paradigmático en este sentido, ya que ha conseguido fijar un territorio a pesar de hacerlo en un contexto políticoadministrativo complicado. Por el contrario, una fórmula personificada también supone una mayor rigidez en lo que se refiere a su constitución y reforma.

Tabla 2. Fórmulas administrativas de cooperación.

\begin{tabular}{|c|c|c|}
\cline { 2 - 3 } \multicolumn{1}{c|}{} & Permanentes & Temporales \\
\hline \multirow{3}{*}{ Personificadas } & Mancomunidades & \\
& Consorcios administrativos \\
& $\begin{array}{c}\text { Sociedades mercantiles } \\
\text { interadministrativas } \\
\text { Fundaciones } \\
\text { Sin personificaciones }\end{array}$ & \\
\hline & Convenios administrativos & $\begin{array}{c}\text { Contratos de río } \\
\text { Comisiones de seguimiento } \\
\end{array}$ \\
\hline
\end{tabular}

Fuente: Elaboración propia

Encontramos otros ejemplos de personificación en espacios interautonómicos que tienen la gestión ambiental como objeto, como el consorcio interautonómico para la gestión coordinada del Parque Nacional de Picos de Europa, creado a través de un convenio entre Asturias, Cantabria y Castilla y León en 2010. También hay que mencionar la Mancomunidad de Bajo Deva, formada por los municipios de Val de San Vicente (Cantabria) y Rivadedeva (Asturias), en este caso centrados en la promoción turística, y más concretamente en la aprobación de un Plan de Dinamización Turística del Bajo Deva.

En el caso de Tres Territoris se ha optado por la fórmula de la asociación, quizás la fórmula personificada más sencilla. No crear una entidad diferenciada supone una mayor flexibilidad, pero también que el proyecto esté sujeto a los vaivenes políticos, los cambios de gobierno en los entes implicados o las presiones de los gobiernos autonómicos. A modo de ejemplo, el conflicto político en Cataluña ha tenido su 
reflejo también en el territorio ${ }^{21}$, aunque es difícil saber en qué medida puede haber afectado - $\mathrm{o}$ vaya a hacerlo en el futuro- a la cooperación entre los gobiernos locales de las tres comunidades.

\section{Reflexiones finales}

Como ya se ha indicado, la cartografía no tiene como única función representar un espacio objetivo, sino también influir en lo subjetivo y, por lo tanto, construir nuevas realidades. Los mapas son construcciones simbólicas que reflejan las relaciones de poder existentes en el momento de su elaboración. Ello es especialmente cierto en los mapas turísticos, que muestran el territorio propio desde el punto de vista del autor. El mapa turístico tiende a representar, priorizar y jerarquizar en función de los intereses individuales de cada uno de los entes promotores. En este sentido, representarán e interpretarán el territorio en función de los intereses propios. El problema surge en territorios que hemos denominado como "de frontera", en el límite político-administrativo entre comunidades autónomas. Dichos espacios fronterizos están dotados de unidad geográfica, y presentan una estrecha interrelación económica, cultural y social por lo que la representación de los diferentes mapas turísticos presenta una contradicción. Representan un espacio propio, pero ciegan una parte del entorno que están promocionando. El caso del macizo de Els Ports, que analizamos aquí, es muy paradigmático, con el agravante que no tenemos dos sino tres comunidades implicadas.

El entorno de Els Ports -en sentido geográfico- presenta una gran complejidad institucional. Existen diferentes niveles administrativos, casi todos ellos con competencias en promoción turística. Por otra parte, en su mayoría promocionan el territorio, representando cartográficamente sólo su propio territorio, lo que produce una visión sesgada e incompleta de su patrimonio y de la oferta turística. La promoción turística es por tanto ineficiente y desaprovecha parte de los activos del

${ }^{21}$ A modo de ejemplo, la prensa local se ha hecho eco de cierta preocupación en los municipios aragoneses con el conflicto en Cataluña: "Incertidumbre en el Matarraña ante la escalada de tensión con Cataluña", La Comarca, 17 de octubre de 2017 [Accesible en https://www.lacomarca.net/incertidumbre-en-el-matarrana-ante-la-escalada-de-tension-concataluna/]; "Malestar en el Matarraña tras el corte de la carretera autonómica que une Aragón y Cataluña", La Comarca, 8 de noviembre de 2017 [Accesible en https://www.lacomarca.net/malestar-en-el-matarrana-tras-el-corte-de-la-carretera-autonomicaque-une-aragon-y-cataluna/; "El PSOE del Matarraña publica un Manifiesto por el Diálogo y la Democracia entre Cataluña y el Estado", La Comarca, 10 de octubre de 2017_[Accesible en https://www.lacomarca.net/el-psoe-del-matarrana-publica-un-manifiesto-por-el-dialogo-y-lademocracia-entre-cataluna-y-el-estado/ 
territorio, provoca duplicidades y no considera las posibilidades en su conjunto. Las dinámicas disgregadoras del territorio tienen una enorme potencia, desde un punto de vista político e institucional.

En este contexto, la iniciativa que analizamos -Tres Territoris- es un gran paso en la consideración del territorio en su conjunto, ya que avanza en la cooperación y coordinación de esfuerzos en promoción turística. Un elemento fundamental en este sentido es la construcción de un mapa del territorio, que permite visualizar gran parte del territorio. Aun así, sólo tres de las seis comarcas participan en el proyecto, por lo que aunque se trata de una iniciativa muy importante, no consigue aunar a todos los agentes del territorio. El proyecto, aún muy reciente y que necesitará consolidarse, puede suponer un importante paso para generar una visión del territorio en su conjunto y articular un espacio transfronterizo que tiene intereses comunes. La fórmula escogida para articular la cooperación -una asociación- hace que dependa en gran medida del próximo ciclo político, aunque sería muy positivo que la iniciativa se consolidara. En este sentido en agosto de 2018 se firmó el protocolo de creación del Parc Pirinenc de les Tres Nacions, que reúne cuatro parques nacionales de España, Francia y Andorra, con el objetivo de convertirse en un instrumento de promoción turística y dinamización, y de mejora de los espacios protegidos. Es paradójico que en un contexto similar encontremos más dificultades para la cooperación interautonómica que entre Estados. El proyecto de Tres Territoris es una iniciativa que, aunque a menor escala, debería consolidarse y fortalecerse.

\section{Bibliografía}

Almirón, A.; Troncoso, C.; Lois, C. (2007): Promoción turística y cartografía. La Argentina turística en los mapas de la Secretaría de Turismo de la Nación (1996-2004), Investigaciones geográficas, 62, 138-154.

[https://doaj.org/article/3c9910c8871842288b73e561f3b37836]

Aja, E. (2014): Estado Autonómico y reforma federal. Madrid, Alianza Editorial.

Balsa Barreiro, J.; Lois González, R. C. (2010): Particularidades y estado actual de la cartografía turística oficial en Galícia. Cuadernos de turismo, 26, 25-46. [https://revistas.um.es/turismo/article/view/116261]

Cànoves, G.; Blanco-Romero, A.; Vera-Rebollo, J. F.; Prat, J. Ma (2017): Caracterización y dinámicas de los sectores productivos en el territorio: evolución, cambios y nuevas realidades en el modelo turístico. En Farinós Dasí, J.; Olcina Cantos, J. (Eds. y Coords.): Geografía regional de España. Espacio y comunidades. Valencia, PUV-Tirant lo Blanch.

Capellà-Miternique, H. (2002): El espejismo del turismo en tres áreas rurales: Terra Alta, Matarranya y Els Ports. En VVAA: Los espacios rurales entre hoy y mañana. Actas del XI Coloquio de Geografía Rural. Santander, Universidad de Cantabria.

Cors, M. (2009): Patrimoni rural i turisme. En VVAA: Atles del Turisme a Catalunya. Mapa nacional de l'oferta i els productes turístics. Barcelona, Generalitat de Catalunya. [http://www.ub.edu/mapaturismecat/ARTS/116.html] 
Domínguez-Mújica, J. (2007): La cartografía en la promoción turística de Canarias (18801970). Boletín de la A.G.E, 44, 279-300.

[https://bage.age-geografia.es/ojs/index.php/bage/article/view/618]

Farinelli, F. (2003): Geografia: un'introduzione ai modelli del mondo. Turin, Einaudi.

Femenia-Ribera, C.; Mora-Navarro, G.; Benítez-Aguado, E.; Garrido-Villén, N. (2012): Estudio y análisis de la representación de la línea límite de término municipal según diversas cartografías en la Albufera de Valencia. Scripta Nova. Revista electrónica de Geografía y Ciencias Sociales, XVII, 448.

[https://revistes.ub.edu/index.php/ScriptaNova/article/view/14938]

Franquesa, J. (2012): Estrategias patrimoniales en el contexto español: una clasificación. Apuntes: Revista de Estudios sobre Patrimonio Cultural, 25, 2, 334-351. [https://revistas.javeriana.edu.co/index.php/revApuntesArq/article/view/8816]

Galindo Caldés, R. (2018): Els problemes relacionats amb el fet fronterer: algunes disfuncions. En Tort-Donada, J.; Galindo Caldés, R. (Dirs.): L'articulació geogràfica i jurídica dels municipis fronterers: radiografia de la cooperación en els límits autonòmics entre Catalunya, Aragó i la Comunitat Valenciana. Barcelona: EAPC. [DOI: $10.2436 / 10.8030 .03 .14]$

Galindo Caldés, R. (2018b): La percepció del fet fronterer, en Tort Donada, J.; Galindo Caldés, R. (Dirs.): L’articulació geogràfica i jurídica dels municipis fronterers: radiografia de la cooperación en els límits autonòmics entre Catalunya, Aragó i la Comunitat Valenciana. Barcelona: EAPC. [DOI: 10.2436/10.8030.03.14]

García Morales, M. J. (2006): Las relaciones intergubernamentales en el Estado Autonómico: estado de la cuestión y problemas pendientes. En García Morales, M. J.; Montilla Martos, J. A.; Arbós Marín, X.: Las relaciones intergubernamentales en el Estado Autonómico. Madrid: CEPC.

González García, I. (2016): El papel de la norma en la colaboración interterrotorial: propuestas de reforma. REAF, 23.

Harley, J. (2001): The new nature of maps: essays in the history of cartography. Baltimore, The Johns Hopkins University Press.

Miranda Guerrero, R. (2006): Cartografía turística: documentos y recursos para la expresión espacial del turismo. En Miranda Guerrero, R.; González Torreros, L. (Coords.): Perspectivas geográficas del turismo. Guadalajara, Universidad de Guadalajara.

Montoya, V. (2007): El mapa de lo invisible. Silencios y gramática del poder en la cartografía. Universitas Humanística, 63, 155-179.

Navas, T. (2016): La cartografía turística de Barcelona i la construcció d'un relat urbà (segles XIX i XX). En Palau Rubio, S. (Dir.): Destinació BCN: Història del turisme a la ciutat de Barcelona. Barcelona, Efadós.

Pallarés-Cifré, M. Á. (2013): Turismo cinegético en la comarca del Baix Maestrat. Proyecto fin de carrera. Universitat Politècnica de València.

Pérez Guerra, R.; Ceballos Martín, M. (2009). La configuración del Derecho del turismo autonómico español en el ordenamiento jurídico administrativo-constitucional. Revista Aragonesa de Administración Pública, 35, 455-518. 
Teruel, L.; Viñals, M. J.; Morant, M. (2014): Análisis del turismo activo en la Comunitat Valenciana. En VVAA: XVII Congreso Internacional de Turismo Universidad Empresa. Valencia, Fundación Universidad Empresa.

Torres-Solé, T.; Sala-Ríos, M.; Farré-Perdiguer, M. (2015): Grado de sostenibilidad de los ámbitos turísticos catalanes. PASOS. Revista de Turismo y Patrimonio Cultural, 13, 6, 1451-1462.

[https://repositori.udl.cat/bitstream/handle/10459.1/49414/023702.pdf?sequence=1\&isAllo wed $=\mathrm{y}]$

Vilalta Reixach, M. (2018): La necessitat d'articular jurídicament la cooperación: tècniques i instruments. En Tort Donada, J.; Galindo Caldés, R. (Dirs.): L'articulació geográfica i jurídica dels municipis fronterers: radiografia de la cooperación en els límits autonòmics entre Catalunya, Aragó i la Comunitat Valenciana. Barcelona, EAPC. [DOI: $10.2436 / 10.8030 .03 .14]$

Vilanova, O. (2014): Ecomuseologia: d'identitats i territoris. Un museu més enllà del museu. HER\&MUS, VI, 11, 50-56. [http://hdl.handle.net/10459.1/58330]. 